\title{
Bifidobacterium animalis subsp. lactis A6 Alleviates Obesity Associated with Promoting Mitochondrial Biogenesis and Function of Adipose Tissue in Mice
}

\author{
Yanxiong Huo ${ }^{1}$, Xuhong $\mathrm{Lu}^{2}{ }^{2}$, Xiaoyu Wang ${ }^{2}$, Xifan Wang ${ }^{1}$, Lingli Chen ${ }^{1}$, Huiyuan Guo ${ }^{3}$, \\ Ming Zhang ${ }^{4, *(1)}$ and Yixuan $\mathrm{Li}^{1, *}$ \\ 1 Beijing Advanced Innovation Center for Food Nutrition and Human Health, College of Food Science \& \\ Nutritional Engineering, China Agricultural University, Beijing 100083, China; \\ huoyanxiong195615@163.com (Y.H.); wangxfan@126.com (X.W.); chenlingli89@163.com (L.C.) \\ 2 Key Laboratory of Functional Dairy, Co-constructed by ministry of Education and Beijing Municipality, \\ College of Food Science \& Nutritional Engineering, China Agricultural University, Beijing 100083, China; \\ luxuhong@cau.edu.cn (X.L.); xy.wang@cau.edu.cn (X.W.) \\ 3 Beijing Laboratory of Food Quality and Safety, College of Food Science and Nutritional Engineering, China \\ Agricultural University, Beijing 100083, China; guohuiyuan@cau.edu.cn \\ 4 School of Food and Chemical Engineering, Beijing Technology and Business University, Beijing 100048, China \\ * Correspondence: zhangming@th.btbu.edu.cn (M.Z.); liyixuan9735@126.com (Y.L.); \\ Tel.: +86-10-6273-6344 (M.Z. \& Y.L.)
}

Received: 13 February 2020; Accepted: 11 March 2020; Published: 25 March 2020

\begin{abstract}
Probiotics are widely known for their health benefits. Mitochondrial dysfunction is related to obesity. The aim of this study was to illuminate whether Bifidobacterium animalis subsp. lactis A6 (BAA6) could improve obesity due to increased mitochondrial biogenesis and function of adipose tissues. Four-week-old male C57BL/6 mice were fed with a high-fat diet (HFD) for 17 weeks. For the final eight weeks, the HFD group was divided into three groups including HFD, HFD with BAA6 (HFD + BAA6 group), and HFD with Akkermansia muciniphila (AKK) (HFD + AKK group as positive control). The composition of the microbiota, serum lipopolysaccharides (LPS), and mitochondrial biosynthesis and function of epididymal adipose tissues were measured. Compared with the HFD group, body weight, relative fat weight, the relative abundance of Oscillibacter and Bilophila, and serum LPS were significantly decreased in the HFD + BAA6 and HFD + AKK groups $(p<0.05)$. Furthermore, the addition of BAA6 and AKK increased the expression of peroxisome proliferator-activated receptor $\gamma$ coactivator $1 \alpha$ (PGC-1 $\alpha$ ) (by 21.53- and 18.51-fold), estrogen-related receptor $\alpha(E R R \alpha)$ (by 2.83- and 1.24-fold), and uncoupling protein-1 (UCP-1) (by 1.51- and 0.60-fold) in epididymal adipose tissues. Our results suggest that BAA6 could improve obesity associated with promoting mitochondrial biogenesis and function of adipose tissues in mice.
\end{abstract}

Keywords: Bifidobacterium animalis subsp. lactis A6; obesity; mitochondrial biogenesis and functions; lipopolysaccharides; tumor necrosis factor $\alpha$

\section{Introduction}

Obesity is associated with increasing occurrence of metabolic diseases, such as type 2 diabetes [1], as well as cardiovascular and cerebrovascular diseases [2]. Alleviation of obesity can be a means to reduce the risk of metabolic diseases [3]. Currently, the main approaches to treat obesity include diet regulation, exercise, surgical treatment, and drug modulation [4]. Although surgical or medical treatments can significantly reduce body weight, there are many side effects such as portal thrombosis, bleeding, and leak $[5,6]$. 
Probiotics intervention can confer great safety and high levels of effectiveness [7]. Given the growing evidence implicating the positive effects of probiotics on obesity treatment, this method is attracting more and more attention [4,8]. Many probiotic strains of the genera Bifidobacterium and Lactobacillus have anti-obesity effects on different mouse models of obesity $[9,10]$. Bifidobacterium animalis subsp. lactis CECT 8145 strain has strong fat-reduction capacity and it modulates lipid metabolism in an obese mouse model [11]. Lactobacillus acidophilus NS1 can alleviate HFD-induced obesity in mice by improving lipid metabolism and insulin sensitivity through an AMP-activated protein kinase [12]. Bifidobacterium animalis subsp. lactis I-2494 was shown to be able to decrease body weight gain and balance gut microbiota composition [13]. It was reported that Akkermansia muciniphila (AKK) could decrease the adipose tissue mass and alleviate obesity [14,15]. At present, the mechanisms of probiotics improving obesity are mainly related to fat metabolism, insulin sensitivity, and intestinal microbiota composition. Mitochondria act as the signaling platform to orchestrate integrated physiological responses to maintain health [16]. It is known that mitochondria lie at the center of lipid metabolism, involving processes such as decarboxylation and $\beta$-oxidation of fatty acids [17], which are also important sites for producing heat [18]. Some studies found that the reduction of mitochondrial biogenesis and impairment of mitochondrial function can accelerate obesity [19]. There is evidence that the mitochondrial contents and oxidation capacity of fatty acids are lower in obese patients [20]. The gene operon of Lactobacillus plantarum may be helpful for mitochondrial fatty acid oxidation [21]. Previous studies showed that estradiol can alleviate obesity through increasing mitochondrial biogenesis and function [22]. However, the relationship between probiotics and mitochondrial biosynthesis and function is less studied in improving obesity.

Bifidobacterium animalis subsp. lactis A6 (BAA6), a probiotic strain, is isolated from the feces of a centenarian. It was demonstrated that BAA6 has high acid resistance to low $\mathrm{pH}$, which is critical for it surviving through gastric juice [23]. It is unclear whether BAA6 could alleviate obesity and whether this is associated with increasing mitochondrial biogenesis and function of adipose tissues. In this study, we hypothesized that BAA6 could ameliorate obesity related to improving mitochondrial biogenesis and function of adipose tissues.

\section{Results}

\subsection{BAA6 Accelerated Body Weight and Fat Mass Loss and Changed Serum Lipid Profile Level in Obese Mice}

To understand the effect of BAA6 in ameliorating obesity in mice, we firstly measured food intake of the mice. Compared with the HFD group, there was no significant difference on the weekly food intake of mice after gavage of BAA6 and AKK $(p>0.05)$ (Tables S1-S3, Supplementary Materials). Then, we analyzed the effect of BAA6 treatment on the levels of body weight, fat mass, relative lean weight, and serum lipid profiles of mice. The levels of final body weight, body weight gain, and fat mass were higher in the HFD group than the normal diet (ND) group $(p<0.05)$, which were lower in the HFD + BAA6 and HFD + AKK groups compared with the HFD group $(p<0.05)$ (Figure 1A,B and Figure S1A, Supplementary Materials). Administration of BAA6 and AKK in HFD-fed mice resulted in a lower relative fat weight and higher relative lean weight compared to the HFD group $(p<0.05)$ (Figure 1C and Figure S1B, Supplementary Materials). Meanwhile, the HFD group showed higher levels of serum triglyceride (TG), total cholesterol (TC), and low-density lipoprotein cholesterol (LDL-C) than ND group $(p<0.05)$. The concentrations of serum TG, TC, and LDL-C in the HFD + BAA6 and HFD + AKK groups had no significant difference from those in the HFD group $(p>0.05)$ (Figure 1D-F). Furthermore, we examined the effect of BAA6 on insulin resistance using an intraperitoneal glucose tolerance test (GTT) and insulin tolerance test (ITT). As shown in Figure S2A,B (Supplementary Materials), GTT and ITT were improved in the HFD + BAA6 and HFD + AKK groups. These results suggested that BAA6 treatment could reduce body weight and fat mass. 

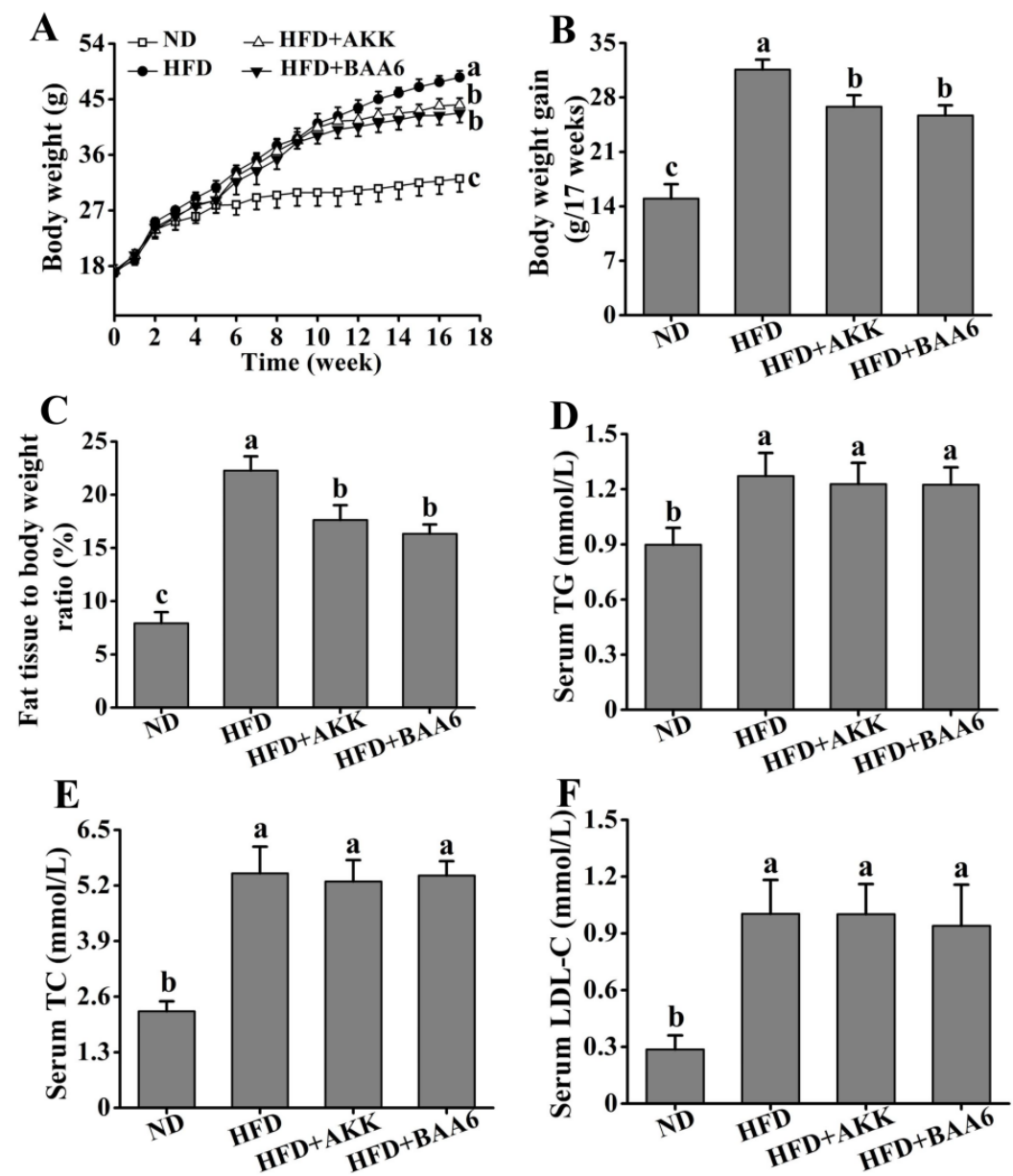

Figure 1. Effects of oral administration of Bifidobacterium animalis subsp. lactis A6 (BAA6) or Akkermansia muciniphila (AKK) on metabolic parameters in high-fat diet (HFD)-fed mice. (A) Body weight, (B) body weight gain, (C) relative adipose tissue, and serum levels of (D) total triglyceride (TG), (E) total cholesterol (TC), and (F) low-density lipoprotein cholesterol (LDL-C) following daily treatment with $10^{9}$ colony-forming units (CFU)/kg of BAA6 or AKK. Values are expressed as means \pm SD $(n=6)$. Bars with different lowercase letters denote significant differences among groups $(p<0.05)$. HFD, fed high-fat diet for 17 weeks; HFD + BAA6, fed high-fat diet and treated with Bifidobacterium animalis subsp. lactis A6 for the final eight weeks; HFD + AKK, fed high-fat diet and treated with Akkermansia muciniphila for the final eight weeks; ND, fed normal diet for 17 weeks.

\subsection{BAA6 Affected Lipid Metabolism of Obese Mice}

To explore the effect of BAA6 on lipid metabolism, the lipid synthesis-related and catabolism-related genes and proteins in mice were measured. We firstly investigated lipid metabolism in the epididymal adipose tissues. Fas messenger RNA (mRNA) and fatty acid synthase (FAS) protein expression levels of epididymal lipid synthesis in the ND group were not significantly different from those in the HFD group $(p>0.05)$. Meanwhile, administration with BAA6 and AKK in HFD mice did not change significantly the Fas mRNA and FAS protein expression levels, compared to the HFD group $(p>0.05)$ (Figure 2A,C). The levels of $H s l$ mRNA and hormone-sensitive lipase (HSL) protein expression related to epididymal lipid catabolism are shown in Figure 2B,D. The expression levels of Hsl mRNA and HSL protein in epididymal adipose tissue were remarkably downregulated in the HFD group compared with the HFD + BAA6 or HFD + AKK groups $(p<0.05)$. Furthermore, we analyzed lipid metabolism in the hepatic tissues. As shown in Figure S3A-D (Supplementary Materials), the levels of Fas mRNA and FAS protein were significantly lower in the ND group than in the HFD group $(p<0.05)$. However, the $\mathrm{Hsl}$ mRNA and HSL protein expression levels were significantly higher in the ND group than in 
the HFD group $(p<0.05)$. Compared with the HFD group, there was no significant effect of BAA6 and AKK treatments on the expression of Fas, FAS, Hsl, and HSL in liver $(p>0.05)$. Overall, these results showed that BAA6 could increase lipid catabolism in epididymal adipose tissues.
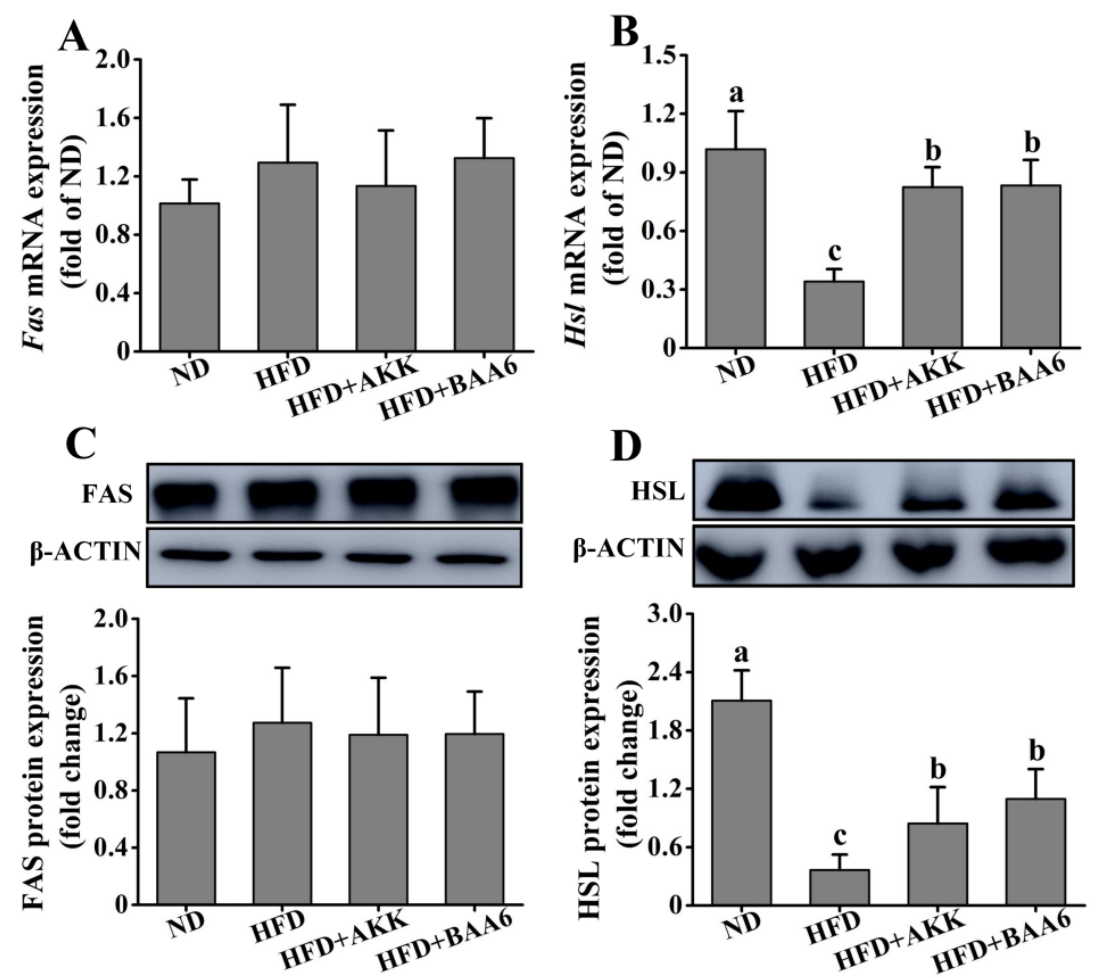

Figure 2. Effects of BAA6 or AKK on lipid metabolism for epididymal adipose tissues in HFD-fed mice. Messenger RNA (mRNA) expression levels of (A) fatty acid synthase (Fas) and (B) hormone-sensitive lipase $(\mathrm{Hsl})$, and protein expression levels of (C) FAS and (D) HSL following daily treatment with $10^{9}$ $\mathrm{CFU} / \mathrm{kg}$ BAA6 or AKK. Values are expressed as means $\pm \mathrm{SD}(n=6)$. Bars with different lowercase letters denote significant differences among groups $(p<0.05)$.

\subsection{BAA6 Modulated Gut Microbiota of Obese Mice}

The gut microbiota plays a key role in metabolic disorder, especially lipid metabolism [24]. Thus, we wanted to explore the effect of BAA6 on the intestinal microbiota. Firstly, the relative abundance of the gut microbiota was analyzed. At the genus level, Oscillibacter, Bilophila, Mucispirillum, Anaerotruncus, Blautia, Sphingomonas, and norank_f_Bacteroidates_S24-7_group in the ND group were found to be differently abundant, compared with the HFD group. Meanwhile, there was a significant reduction in relative abundance of Oscillibacter (by 1.86- and 1.94-fold), Bilophila (by 3.94- and 5.30-fold), Anaerotruncus (by 1.30- and 0.65-fold), and Sphingomonas (by 1.01- and 2.55-fold), as well as a significant increase in norank_f_Bacteroidates_S24-7_group (by 0.81- and 0.60-fold) and Lactobacillus (by 2.63- and 5.01-fold) in the HFD + BAA6 and HFD + AKK groups, when compared with the HFD group (Figure 3A and Figure S4, Supplementary Materials). Furthermore, principal component analysis (PCA) was used to investigate the phylogenetic differences within the gut microbiota (Figure 3B). The HFD group had a distinct microbiota composition that clustered separately from the ND, HFD + BAA6, and HFD + AKK groups with the first principal component (PC1) explaining 21.81\% variation and PC2 explaining $10.67 \%$ variation $\left(R^{2}=0.599 ; p=0.001\right)$. To further analyze the pattern of the microbiota, linear discriminant analysis (LDA) effect size (LEfSe) analysis was employed. Based on the comparison between the ND and HFD groups, 12 key phylotypes were identified as enriched within the ND group, while 26 key phylotypes were identified as enriched within the HFD group such as Oscillibacter, Bilophila, Mucispirillum, Anaerotruncus, Sphingomonas, and Blautia (Figure 3C). Furthermore, based on the comparison among HFD, HFD + BAA6, and HFD + AKK groups, five key phylotypes were 
identified as enriched within the HFD + BAA6 group such as norank_f_Bacteroidales_S24-7_group, five key phylotypes were identified as enriched within the HFD + AKK group such as Lactobacillus, and 15 key phylotypes were identified as enriched within the HFD group such as Oscillibacter, Bilophila, Anaerotruncus, and Sphingomonas (Figure 3D). Overall, these data strongly demonstrated that BAA6 could reduce the relative abundance of LPS-related strains.

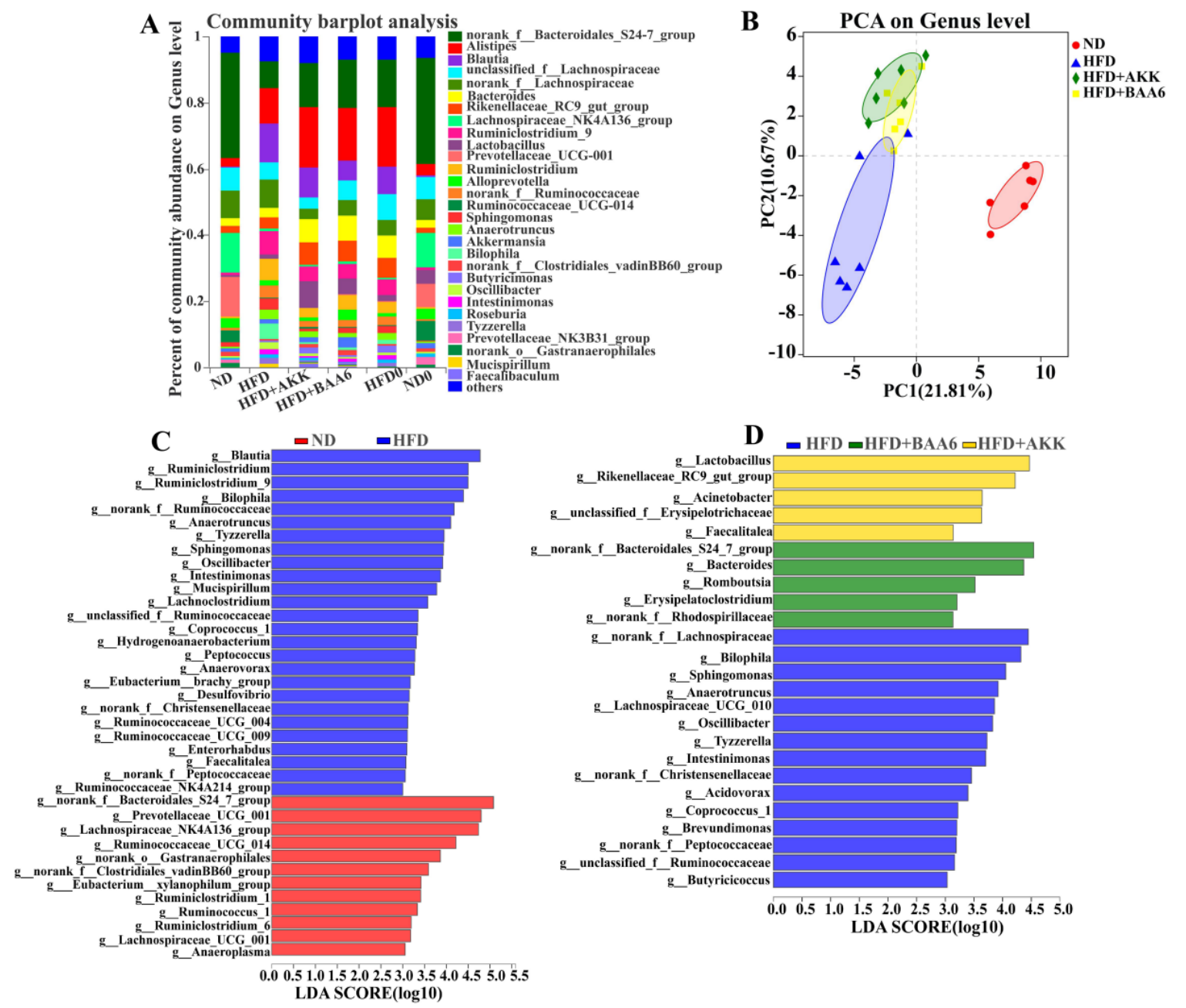

Figure 3. Effects of BAA6 or AKK on gut microbiota in HFD-fed mice. (A) Relative abundance of the gut microbial community at the genus level. (B) Principal component analysis (PCA) score plots at the genus level. (C) Histogram of the linear discriminant analysis (LDA) scores between the ND and HFD groups, and (D) histogram of LDA scores among the HFD, HFD + AKK, and HFD + BAA6 groups. The differences with an LDA score greater than three are considered significant. $n=6$ mice/group. HFD0, fed high-fat diet for nine weeks; ND0, fed normal diet for nine weeks.

\subsection{BAA6 Reduced Serum LPS and Inflammatory Cytokines in Fat Tissues of Obese Mice}

Obesity is associated with the state of chronic inflammation and abnormal production of proinflammatory mediators, such as tumor necrosis factor $\alpha$ (TNF- $\alpha)$. We confirmed the efficacy of BAA6 in decreasing the LPS-producing microbiota. Evidence strongly suggests that the overgrowth of LPS-related strains in the gut is closely related to the increase in serum LPS. LPS is a strong stimulator for the release of TNF- $\alpha$ [25]. Thus, we wanted to explore the relationship between LPS and TNF- $\alpha$. The concentration of serum LPS was firstly explored. Mice in the HFD group exhibited an elevated level of serum LPS, which was lower in the ND group $(p<0.05)$. Compared to the HFD group, the serum LPS concentration was remarkably decreased in the HFD + BAA6 and HFD + AKK groups $(p<0.05)$ (Figure 4A). Then, we explored the TNF- $\alpha$ concentration in the epididymal adipose tissues. As shown 
in Figure 4B, the TNF- $\alpha$ concentration in the HFD group was remarkably increased, compared with the ND group $(p<0.05)$. However, administration with BAA6 and AKK significantly decreased the TNF- $\alpha$ level $(p<0.05)$. We found a change in serum LPS level consistent with the change in TNF- $\alpha$ concentration in the epididymal fat tissues. To further investigate how LPS could induce the change in TNF- $\alpha$, the levels of phosphorylation of c-Jun N-terminal kinase (JNK) and extracellular signal-regulated kinase 1/2 (ERK1/2) were explored. As shown in Figure 4C, the HFD group had a higher phosphorylated $(p)-\mathrm{JNK} / \mathrm{JNK}$ ratio compared to the ND group $(p<0.05)$. Furthermore, BAA6 and AKK supplementation significantly decreased the $p$-JNK/JNK proportion $(p<0.05)$. The ratio of $p$-ERK1/2/ERK1/2 in the HFD group was not significantly different from the ND group $(p>0.05)$. Meanwhile, the levels of $p$-ERK1/2/ERK1/2 in the HFD + BAA6 and HFD + AKK groups had no significant difference from those in the HFD group $(p>0.05)$ (Figure 4D). These data indicated that BAA6 could decrease TNF- $\alpha$ expression in epididymal fat, which was likely to be associated with inhibiting the JNK signaling pathway through reducing serum LPS level.
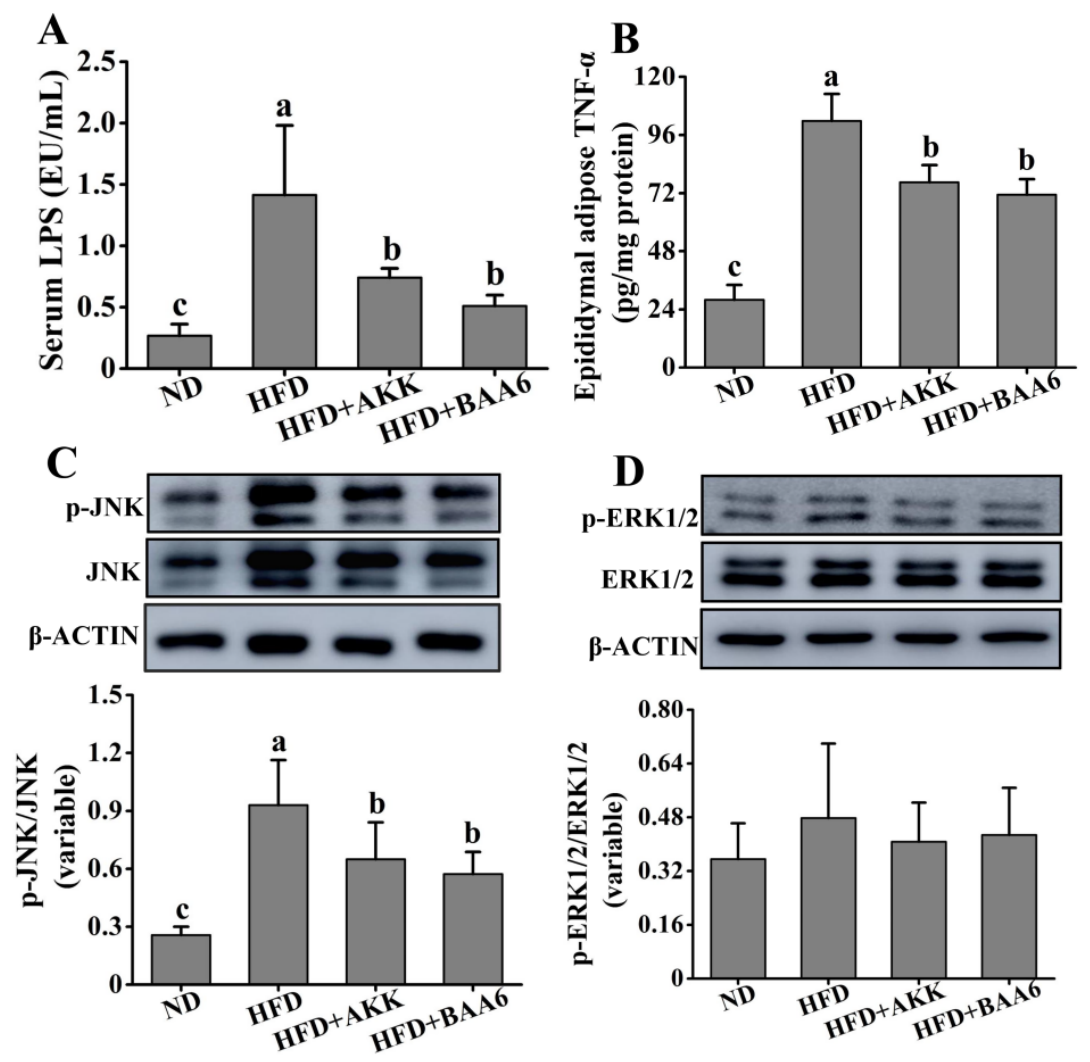

Figure 4. Effects of oral administration of BAA6 or AKK on inflammation in HFD-fed mice. (A) The level of serum lipopolysaccharides (LPS). (B) Tumor necrosis factor $\alpha$ (TNF- $\alpha$ ) concentration in epididymal adipose tissues. Protein expression levels of $(\mathbf{C})$ phosphorylated c-Jun N-terminal kinase ( $p$-JNK)/JNK and (D) phosphorylated extracellular signal-regulated kinase 1/2 ( $p$-ERK1/2)/ERK1/2 in epididymal fat tissues following daily treatment with $10^{9} \mathrm{CFU} / \mathrm{kg}$ BAA6 or AKK. Values are expressed as means $\pm \mathrm{SD}$ $(n=6)$. Bars with different lowercase letters denote significant differences among groups $(p<0.05)$.

2.5. BAA6 Increased Endothelial Nitric Oxide Synthase (eNOS) Expression and Mitochondrial Biogenesis in Fat Tissues of Obese Mice

TNF- $\alpha$ could regulate eNOS expression [26], and several studies demonstrated that eNOS could promote mitochondrial biogenesis [27]. Moreover, mitochondria are the main site of catabolism. Therefore, we investigated the effect of BAA6 on eNOS expression and mitochondrial biosynthesis in epididymal fat tissues. The levels of $e$ Nos mRNA and eNOS protein expression were firstly measured in epididymal adipose. The levels of $e$ Nos mRNA and eNOS protein expression in the HFD group were 
lower than those in the ND group $(p<0.05)$. After adding BAA6 and AKK, the magnitudes of $e$ Nos mRNA and eNOS protein expression were markedly increased compared with the HFD group $(p<0.05)$ (Figure 5A,D). eNOS is involved in the activation of peroxisome proliferator-activated receptor $\gamma$ coactivator $1 \alpha$ (PGC-1 $\alpha)$ expression. PGC- $1 \alpha$ is a master regulator of cellular metabolism, and it controls the expression of mitochondrial genes. Next, we investigated Pgc-1 $\alpha$ mRNA and PGC-1 $\alpha$ protein expression in epididymal fat of obese mice. As shown in Figure 5B,E, the levels of Pgc-1 $\alpha$ mRNA and PGC-1 $\alpha$ protein expression were lower in the HFD group than in the ND group $(p<0.05)$. Compared with the HFD group, Pgc- $1 \alpha$ mRNA and PGC- $1 \alpha$ protein expression was significantly increased in the HFD + BAA6 and HFD + AKK groups $(p<0.05)$. Nuclear respiratory factor-1 (NRF-1) was identified as an important target for the induction of mitochondrial biogenesis by PGC- $1 \alpha$. Thus, we further explored the levels of Nrf-1 mRNA and NRF-1 protein expression. The levels of Nrf-1 mRNA and NRF-1 protein expression were lower in the HFD group compared to the ND group $(p<0.05)$. After administration of BAA6 and AKK, Nrf-1 mRNA and NRF-1 protein expression levels were significantly increased compared to the HFD group $(p<0.05)$ (Figure 5C,F). Overall, these results showed that BAA6 increased mitochondrial biogenesis, which was associated with increased eNOS expression.
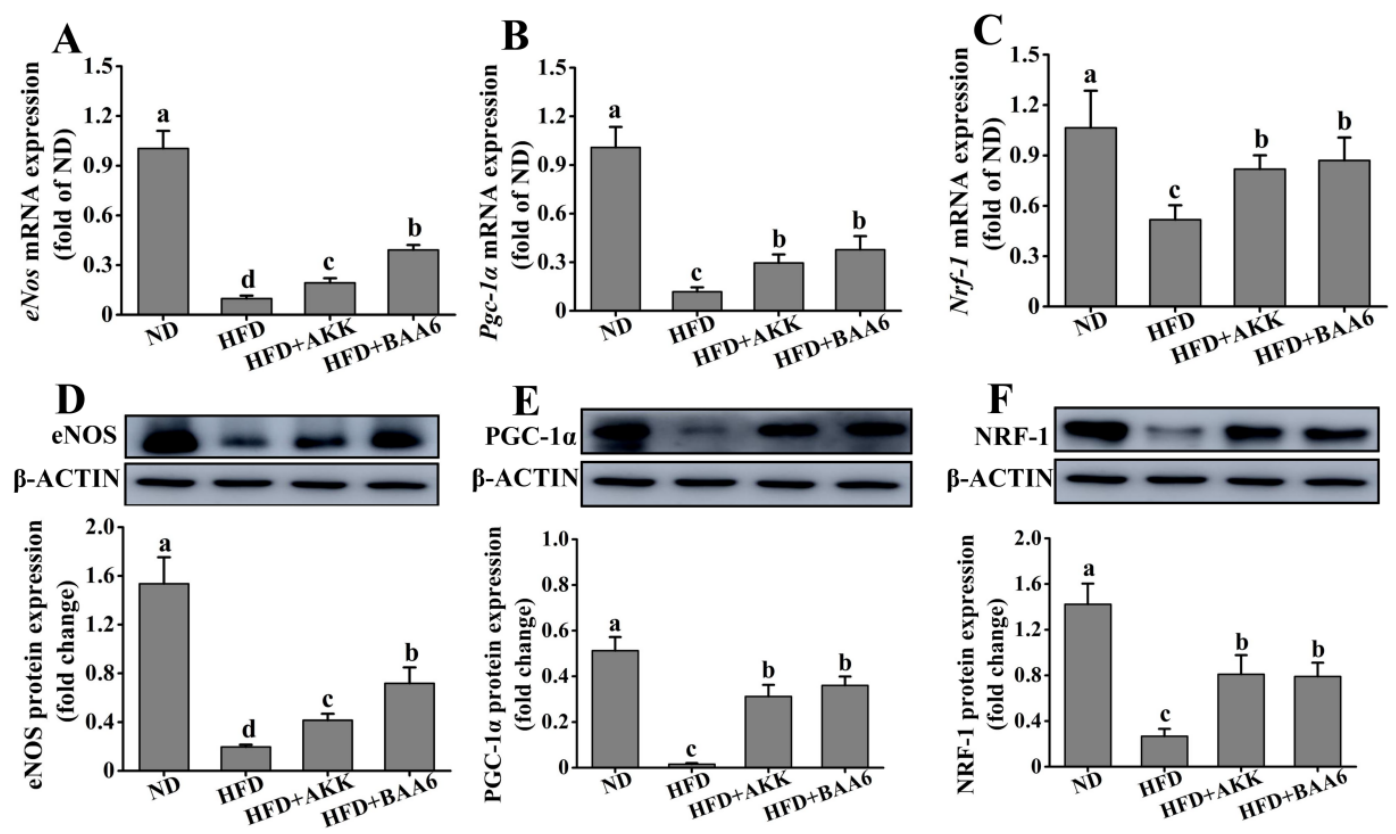

Figure 5. Effects of oral administration of BAA6 or AKK on endothelial nitric oxide synthase (eNOS) expression and mitochondrial biogenesis of epididymal adipose tissues in HFD-fed mice. (A) mRNA expression levels of endothelial nitric oxide synthase (eNos), (B) peroxisome proliferator-activated receptor $\gamma$ coactivator $1 \alpha(P g c-1 \alpha)$, and $(\mathbf{C})$ nuclear respiratory factor-1 (Nrf-1) and protein expression levels of (D) eNOS, (E) PGC-1 $\alpha$, and (F) NRF-1 following daily treatment with $10^{9} \mathrm{CFU} / \mathrm{kg}$ BAA6 or AKK. Values are expressed as means $\pm \mathrm{SD}(n=6)$. Bars with different lowercase letters denote significant differences among groups $(p<0.05)$.

\subsection{BAA6 Reinforced Mitochondrial Function in Fat Tissues of Obese Mice}

Next, we examined the effect of BAA6 on the mitochondrial function of epididymal fat tissues. The $\beta$-oxidation and thermogenic function of mitochondria were studied. Estrogen-related receptor $\alpha(E R R \alpha)$ acts as a regulator of $\beta$-oxidation via its control of the medium-chain acyl-coenzyme $\mathrm{A}$ dehydrogenase promoter. We firstly examined Err $\alpha$ mRNA and ERR $\alpha$ protein levels in epididymal fat. The HFD group showed a striking reduction in Err $\alpha$ mRNA and ERR $\alpha$ protein levels, when compared with the ND group $(p<0.05)$. However, Err $\alpha$ mRNA and ERR $\alpha$ protein levels were significantly increased in the HFD + AKK and HFD + BAA6 groups compared to the HFD group $(p<0.05)$ (Figure 6A,C). Then, we explored $\beta$-hydroxyacyl CoA dehydrogenase $(\beta$-HAD) and carnitine 
palmitoyl transferase I (CPT-I) enzyme activities, which are involved in the regulation of $\beta$-oxidation. The $\beta$-HAD and CPT-I activities were lower in the HFD group compared to the ND group $(p<0.05)$. After administration with BAA6 and AKK, the $\beta$-HAD and CPT-I activities were significantly increased compared to the HFD group $(p<0.05$ ) (Figure 6E,F). Furthermore, an elevation in mitochondrial uncoupling could dissipate energy as heat and contribute to an increase in fatty acid utilization. Thus, we investigated uncoupling protein-1 (Ucp-1) mRNA and UCP-1 protein expression in epididymal fat tissues. Both Ucp-1 mRNA and UCP-1 protein levels were lower in the HFD group than in the ND group $(p<0.05)$. Mice in the HFD + BAA6 group possessed a more potent effect on upregulating Ucp-1 mRNA and UCP-1 protein compared with the HFD group $(p<0.05)$. Administration of AKK in the HFD group resulted in significantly higher Ucp-1 mRNA expression compared to the HFD group $(p<0.05)$. Although there was no significant difference in UCP-1 protein level $(p>0.05)$, the trend was similar to mRNA expression (Figure 6B,D). Altogether, these data indicated that BAA6 could increase mitochondrial function.
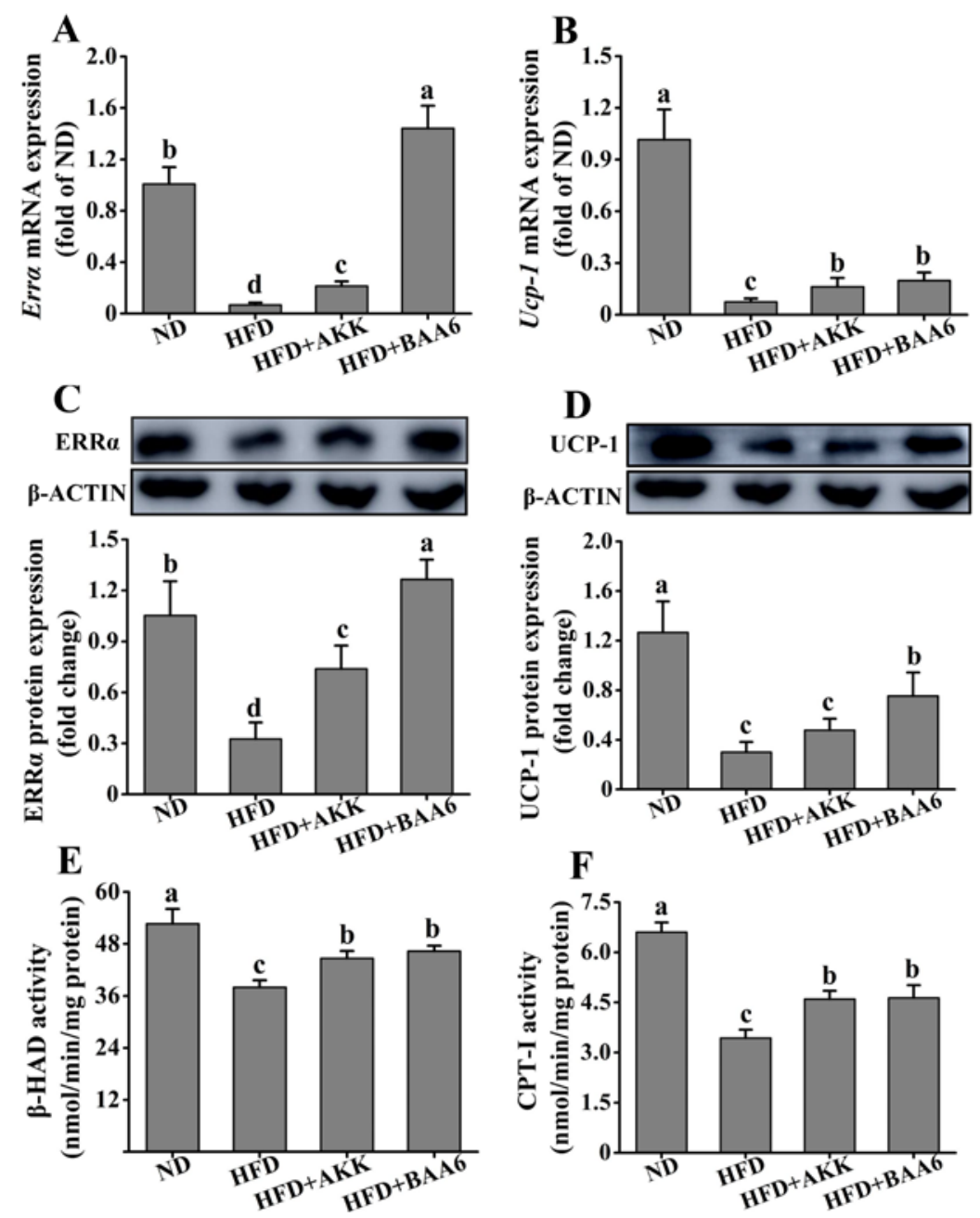

Figure 6. Effects of oral administration of BAA6 or AKK on mitochondrial function of epididymal fat tissues in HFD-fed mice. mRNA expression levels of (A) estrogen-related receptor $\alpha(E r r \alpha)$ and (B) uncoupling protein-1 (Ucp-1), protein expression levels of (C) ERR $\alpha$ and (D) UCP-1, and enzyme activities of (E) $\beta$-hydroxyacyl CoA dehydrogenase ( $\beta$-HAD) and (F) carnitine palmitoyl transferase I (CPT-I) following daily treatment with $10^{9} \mathrm{CFU} / \mathrm{kg}$ of BAA6 or AKK. Values are expressed as means \pm $\mathrm{SD}(n=6)$. Bars with different lowercase letters denote significant differences among groups $(p<0.05)$. 


\section{Discussion}

This study demonstrated the effect of oral administration with probiotic BAA6 on improving obesity. The results showed that supplementation with BAA6 significantly reduced body weight and relative adipose weight, while it increased lipolysis metabolism in adipose tissues, indicating that BAA6 has the potential to improve obesity. Meanwhile, BAA6 showed a better effect on improving obesity than AKK, which was reported to alleviate obesity in previous studies [28]. Previous studies showed that obesity-resistant mice, fed with HFD, had lower body weight and fat gain than obesity-prone mice. Nevertheless, serum lipid profiles in obesity-resistant mice had no remarkable difference from obesity-prone mice during high-fat feeding [29]. Our results also found that there was no significant difference among the HFD, HFD + BAA6, and HFD + AKK groups in terms of serum TG, TC, and LDL-C levels. This phenomenon may be due to the long-term HFD treatment, which maintains serum TG, TC, and LDL-C at a higher level. Although there was intervention due to probiotics like BAA6 and AKK, serum TG, TC, and LDL-C levels were not dramatically reduced in a short time.

The imbalance of the gut microbiota plays an important role in the development of obesity, and obesity is also associated with a chronic inflammatory state [24]. It is now known that inflammation-related obesity is linked to LPS [30]. Song et al. found that HFD treatment could induce higher levels of gut LPS-producing bacteria, especially Bilophila and Oscillibacter [31]. Meanwhile, emerging evidence suggested that the overgrowth of Mucispirillum strains in gut was positively correlated with LPS [32]. Previous clinical and animal experiments confirmed that probiotics could alleviate obesity and improve the composition of gut microbiota [33]. Consistent with these studies, BAA6 intervention significantly decreased the relative abundance of LPS-related bacteria, such as Bilophila and Oscillibacteron. Supplementation with AKK could increase the levels of $\beta$-sitosterol in the gut [34], and $\beta$-sitosterol had positive effects on the growth of Lactobacillus [35]. Thus, this may be the reason that AKK could markedly increase the relative abundance of Lactobacillus in our study. It was reported that Lactobacillus could effectively suppress body weight gain [36] and had anti-inflammatory effects [37]. Hence, the positive effects of AKK may be related to Lactobacillus. Moreover, we found that BAA6 could dramatically increase the relative abundance of Norank_f_Bacteroidales_S24-7_group. Some studies found that Bifidobacterium could increase the relative abundance of Norank_f_Bacteroidales_S24-7_group [38], which was similar to our findings. The norank_f_Bacteroidales_S24-7_group might exert beneficial effects against obesity due to alteration of the gut microbiota [39]. It was also involved in host-microbe interactions which affected gut function and health [40]. When mice were fed with a low-fat diet, the norank_f_Bacteroidales_S24-7_group was abundant [41]. In addition, some research found that the norank_f_Bacteroidales_S24-7_group was strongly correlated with the suppression of inflammatory markers in obese mice [42]. Our data showed that probiotic BAA6 treatment remarkably increased the relative abundance of the norank_f_Bacteroidales_S24-7_group.

Many evidence strongly suggested that the overgrowth of LPS-related strains in gut was closely related to the increase in serum LPS [43]. The leakage of LPS to circulation was based on the high permeability of the intestine [25]. Many studies showed that the mucus layer's integrity had a positive effect on maintaining intestinal permeability. It was shown that the thickness of the mucus layer was decreased, and intestinal permeability was increased in obese mice, particularly due to the increased population of harmful microorganisms [44]. We found that the level of serum LPS was higher in the HFD group than in the ND group, which might be due to the lower mucus layer thickness and higher relative abundance of LPS-related bacteria such as Bilophila, Oscillibacteron, and Mucispirillum. Several strategies, such as the utilization of probiotics, were suggested to be able to regulate gut microbiome dysbiosis by increasing the population of beneficial bacteria while reducing the growth of indigenous pathobionts and opportunistic pathogens $[45,46]$. Cani et al. reported that HFD was associated with lower Bifidobacterium species in the gut of mice [25]. Probiotics exerted beneficial effects on the host by improving intestinal microbial balance and colonization [47]. They might be involved in the stimulation of mucin secretion and reduction of enterocyte apoptosis to improve 
intestinal permeability [48,49]. Faecalibacterium prausnitzii [49] and AKK [50] were negatively correlated with LPS in obesity. Some studies indicated that probiotics could promote the secretion of mucus to reduce intestinal permeability [51]. We observed that administration of BAA6 and AKK in HFD mice decreased serum LPS, which might be due to the higher mucus layer thickness and lower relative abundance of LPS-related bacteria such as Bilophila and Oscillibacter.

A better understanding of the cross-talk among inflammation, adipose tissue, and metabolism energy is crucial for elucidating the underlying mechanism of obesity-related diseases. Moreover, the adipose tissues are major sites for the storage of excess energy and inflammatory response reactions [52]. It is not clear why low-grade inflammation exists, but recent advances revealed a mechanism related to the leakage of LPS from gut [25]. A constantly elevated serum LPS was considered to cause inflammation, dyslipidemia, and metabolic disease [53]. Furthermore, obesity is associated with abnormal TNF- $\alpha$ production of adipose tissues [53]. LPS is a strong stimulator for the release of several cytokines like TNF- $\alpha$, implying its critical role in driving the inflammatory potential of adipocytes [25]. It could induce the production of TNF- $\alpha$ by activating JNK pathways [54]. Our study revealed that the $p$-JNK/JNK ratio in the HFD + BAA6 and HFD + AKK groups was significantly decreased compared to that in the HFD group. We also found that the concentrations of TNF- $\alpha$ in epididymal fat in the HFD + BAA6 and HFD + AKK groups were lower than those in the HFD group, which was likely associated with the regulation of serum LPS by the JNK signaling pathway. TNF- $\alpha$ could be overproduced in the adipose tissues of the obese model, playing an important role in this process. There was a three-fold increase of TNF- $\alpha$ levels in obese individuals [55,56]. Furthermore, the higher level of TNF- $\alpha$ could lead to the downregulation of eNOS [26]. Lower expression of eNOS in adipose tissues is an important risk factor for obesity [51]. Our results also showed significantly lower levels of eNos mRNA and eNOS protein in the HFD group. However, supplementation with BAA6 and AKK in HFD mice could induce eNos mRNA and eNOS protein expression.

As the important site of energy metabolism, defective metabolism of the mitochondria was recently suggested as a major cause of obesity [51]. It was reported that lipid metabolism could be improved by enhancing mitochondrial biogenesis and function [57,58]. Therefore, mitochondrial biogenesis and function are pivotal to mitigate obesity. Several studies demonstrated that eNOS was involved in mitochondrial signaling pathways [59] and promoted mitochondrial biogenesis [27]. eNOS is also involved in the activation of PGC-1 $\alpha$, which is the master regulator of cellular metabolism [60] and controller of mitochondrial biogenesis [61]. Moreover, the content of lipid was noticeably diminished by increasing mitochondrial biogenesis and function [62]. Interestingly, mitochondria in mice lacking the gene encoding endothelial NO synthase were somewhat less densely packed compared to wild-type mice [27]. These changes were accompanied by a reduction of PGC-1 $\alpha$, indicating that basal mitochondrial contents were affected by the loss of eNOS. Our study showed that $P g c-1 \alpha$ gene and PGC-1 $\alpha$ protein levels in epididymal adipose tissues were reduced in the HFD group and markedly elevated by treatments with probiotics BAA6 or AKK in HFD-fed mice. These results indicated that mitochondrial biogenesis and metabolism of epididymal adipose tissues in HFD mice could be improved by BAA6 or AKK treatment. Meanwhile, PGC- $1 \alpha$ could in turn activate the expression of NRF-1 and ERR $\alpha$ [63]. NRF-1 could regulate mitochondrial DNA copy numbers and transcriptional activities [64]. The associated increase in NRF-1 expression coincided with elevated expression of cytochrome $\mathrm{c}$ and enhanced mitochondrial densities [65]; thus, NRF-1 could increase the oxidative respiration of mitochondria. ERR $\alpha$ is the vital step in mitochondrial fatty acid $\beta$-oxidation, and it is considered to be one of the gatekeepers that control the fatty acid $\beta$-oxidation rate in the cell [66]. We observed that addition of probiotics BAA6 and AKK in HFD-fed mice could markedly improve Nrf-1 and Err $\alpha$ mRNA, as well as NRF-1 and ERR $\alpha$ protein expression of epididymal adipose tissues. These findings indicated that mitochondrial fatty acid $\beta$-oxidation in the epididymal adipose tissues of HFD mice could be significantly improved by BAA6 or AKK treatment. Some researchers found that CPT-I and $\beta$-HAD were the key regulatory enzyme in mitochondrial $\beta$-oxidation $[67,68]$. Our study also found that the $\beta$-HAD and CPT-I activities were significantly increased by treatments with probiotics 
BAA6 or AKK in HFD-fed mice, which meant that the effect of mitochondria on fatty acid $\beta$-oxidation was increased by BAA6 or AKK treatment. UCP-1 is an inner mitochondrial membrane protein, which may also be induced by PGC-1 $\alpha$ [69]. Previous studies showed that UCP-1 could uncouple mitochondrial oxidative phosphorylation to produce heat instead of ATP synthesis [18]. The levels of Ucp-1 mRNA and UCP-1 protein in the epididymal adipose tissues of HFD mice were significantly lower than HFD-fed mice administrated with BAA6, which meant that the thermogenic function of mitochondria in the epididymal adipose tissues of HFD mice was improved by BAA6 treatment. Furthermore, the upregulated expression of UCP-1 in adipose tissue could boost heat production, which had positive effects on alleviating obesity [70]. These findings indicate that the probiotic BAA6 has strong potential to promote mitochondrial biogenesis and function to accelerate lipid metabolism, which is similar to the findings by Lei et al. [57] and Tsutsumi et al. [58].

In conclusion, our study demonstrated the beneficial effect of probiotic BAA6 on the alleviation of obesity. We also provided new insight into the relationship between BAA6 and mitochondrial biosynthesis and function of adipose tissues to improve obesity.

\section{Materials and Methods}

\subsection{Preparation of Bacterial Cultures}

BAA6 (CGMCC No. 9273) was isolated from the feces of a centenarian in Bama, Guangxi, China. It was grown anaerobically $\left(100 \% \mathrm{~N}_{2}\right)$ at $37^{\circ} \mathrm{C}$ in a basal liquid medium that contained the following (per liter of deionized water): $10 \mathrm{~g}$ of beef extract, $5 \mathrm{~g}$ of yeast extract, $10 \mathrm{~g}$ of tryptone peptone, $20 \mathrm{~g}$ of glucose, $2 \mathrm{~g}$ of triamine citrate, $2 \mathrm{~g}$ of $\mathrm{K}_{2} \mathrm{HPO}_{4}, 0.5 \mathrm{~g}$ of $\mathrm{MgSO}_{4}, 5 \mathrm{~g}$ of sodium acetate, $0.5 \mathrm{~g}$ of L-cysteine, $0.25 \mathrm{~g}$ of $\mathrm{MnSO}_{4}$, and $1 \mathrm{~mL}$ of Tween-80. The solid medium for BAA6 was based on liquid medium plus agar (15 g, per liter liquid medium).

AKK (JCM 30893) was purchased from the Japan Collection of Microorganisms RIKEN BioResource Research Center, Ibaraki, Japan. It was grown anaerobically $\left(\mathrm{H}_{2}: \mathrm{CO}_{2}: \mathrm{N}_{2}, 1: 1: 8\right)$ at $37^{\circ} \mathrm{C}$ in nutrient broth ( $5 \mathrm{~g}$ of peptone and $3 \mathrm{~g}$ of beef extract, per liter of deionized water). The solid medium for AKK was Columbia blood agar with $5 \%$ horse blood.

The bacteria were cultivated overnight and harvested by centrifuging at $3000 \times \mathrm{g}$ for $15 \mathrm{~min}$ at $4{ }^{\circ} \mathrm{C}$, washed twice with $0.9 \%$ saline solution, and resuspended in $0.9 \%$ saline solution. Bacterial concentration was determined by plate count, which was carried out in the respective growth conditions and above-mentioned solid media.

\subsection{Animals and Diets}

All animal studies were approved by the Animal Experimentation Ethics Committee of the China Agricultural University (Beijing, China). Male C57BL/6 mice ( $n=26$, four weeks old) were purchased from Beijing HFK Bioscience Co. Ltd. (Beijing, China). All animals were acclimated for one week under the following conditions: room temperature $23 \pm 1{ }^{\circ} \mathrm{C}$; humidity $50 \% \pm 5 \%$; 12 -h light/dark cycle. During this period, food and water were provided ad libitum. At the end of the first week, six mice were continually fed with a ND to serve as a control group (ND group, 10\% energy from fat), while the other 20 mice were placed on an HFD (60\% energy from fat) for nine weeks to induce obesity [16]. After a nine-week feeding period with the HFD, the body weights of 18 mice were $20 \%$ more than the mean body weight of mice in the ND group, which suggested that the obesity model was successfully established [71]. Then, they were randomly divided into (1) HFD group ( $n=6$, fed with HFD for the final eight weeks), (2) HFD + BAA6 group ( $n=6$, fed with HFD and treated with BAA6 for the final eight weeks $\left(10^{9} \mathrm{CFU} / \mathrm{kg}\right.$ per day)), (3) HFD + AKK group $(n=6$, fed with HFD and treated with AKK for the final eight weeks ( $10^{9} \mathrm{CFU} / \mathrm{kg}$ per day) as positive control). AKK could alleviate obesity [14], which was positively correlated with anti-inflammation [72], as well as the levels of fat browning, fatty acid oxidation, and heat production [73]. BAA6 and AKK were suspended in $0.9 \%$ saline solution, then administrated by oral gavage daily from the 10th week. Mice in ND and HFD groups were given $0.9 \%$ 
saline solution only. ND and HFD (Table S4, Supplementary Materials) were obtained from Research Diets Inc., New Brunswick, NJ, USA. Body weight and food intake were recorded every week. Mice were fasted overnight then anesthetized with Zoletil ${ }^{\circledR}$ and Rompun ${ }^{\circledR}$. They were sacrificed by cervical dislocation after blood collection. Serum, adipose tissue, and liver tissue were stored at $-80{ }^{\circ} \mathrm{C}$ for further analyses.

\subsection{Body Fat Analysis}

Body fat was determined with the nuclear magnetic resonance system using a Body Composition Analyzer MiniQMR23-060H-I (Shanghai Niumag Corporation, Shanghai, China). It was measured in live conscious mice with ad libitum access to diet, as described previously [74].

\subsection{Lipid Profile Analysis}

Serum levels of TG, TC, and LDL-C were measured by the certified core clinical laboratory at the No. 3 Hospital of Beijing University, who used the respective commercial kits and Chemistry Analyzer (BS-350E) provided by Shenzhen Mindray Biomedical Electronics Co., Ltd. (Shenzhen, China) [75].

\subsection{Glucose Tolerance Test and Insulin Tolerance Test}

For the glucose tolerance test, mice were intraperitoneally injected with glucose at $2 \mathrm{~g}$ per $\mathrm{kg}$ body weight after $12 \mathrm{~h}$ of fasting. For the insulin tolerance test, mice were intraperitoneally injected with insulin at $1 \mathrm{IU}$ per $\mathrm{kg}$ body weight (Eli Lilly and Co., Humalog Insulin) after $6 \mathrm{~h}$ of fasting. In all tests, tail blood glucose levels were measured with a glucometer (TheraSense Freestyle) at the indicated times $(0,15,30,60,90$, and $120 \mathrm{~min})$ after injection.

\subsection{PCR Amplification and Sequencing Analysis of Feces}

Feces bacterial analysis was carried out as described previously [76]. Briefly, total DNA was extracted from the fecal samples using the Feces DNA Extraction kit (BioTeKe, Beijing, China). Fecal DNA samples were used as the template for PCR amplification of the V3-V4 hyper-variable regions of $16 \mathrm{~S}$ ribosomal RNA (rRNA) genes by using the primers 338F (5'-GTGCCAGCMGCCGCGG-3') and 806R (5'-CCGTCAATTCMTTTRAGTTT-3'). PCR amplification was performed on an ABI GeneAmp ${ }^{\circledR} 9700$ PCR System (Applied Biosystems, Foster, CA, USA). Sequencing of the PCR amplification products was performed on an Illumina Miseq platform at Majorbio Bio-Pharm Technology (Shanghai, China).

The processing and bioinformatics analyses of the raw data were performed as described previously [77]. A 97\% similarity cutoff was applied to cluster operational taxonomic units (OTUs) with UPARSE (version 7.1 http://drive5.com/uparse/), and chimeric sequences were identified and removed with UCHIME. The taxonomy of each 16S rRNA gene sequence was analyzed using the RDP Classifier (http://rdp.cme.msu.edu/) against the SILVA (SSU115) 16S rRNA database. Analysis of the composition of microbiomes (ANCOM) was carried out in the software R (version 3.6.1). Furthermore, PCA was performed using the R package. The LEfSe analysis (http://huttenhower.sph.harvard.edu/lefse/) was performed to identify the highly dimensional gut microbes with a threshold of 3.0 on the LDA score for discriminative features. Differences were considered to be significant at $p<0.05$.

\subsection{Determination of Endotoxin}

Serum LPS was assessed using a quantitative Chromogenic End-point Tachypleus Amebocyte Lysate assay kit (Xiamen Houshiji, China) as previously described [78].

\subsection{Determination of TNF- $\alpha$ Level in Epididymal Adipose Tissues}

TNF- $\alpha$ level in epididymal adipose tissues was determined using the Mouse TNF- $\alpha$ ELISA Kit (ExCell Biology, Shanghai, China), according to the manufacturer's instruction [79]. The protein 
concentrations were measured by Pierce ${ }^{\mathrm{TM}}$ BCA Protein Assay Kit (Thermo Fisher Scientific, Rockford, MI, USA).

\subsection{Activity Assay for $\beta$-Hydroxyacyl CoA Dehydrogenase and Carnitine Palmitoyl Transferase I}

$\beta$-HAD activity was assayed in whole lysates prepared from frozen epididymal adipose tissues as described previously [80]. Firstly, $40 \mu \mathrm{L}$ of homogenate $(1 \mathrm{mg} / \mathrm{mL})$ was added to a cuvette, which was then was brought to a final volume of $670 \mu \mathrm{L}$ with $800 \mu \mathrm{L}$ of $50 \mathrm{mmol} / \mathrm{L}$ imidazole $(\mathrm{pH} 7.4)$ and $10 \mu \mathrm{L}$ of $1.5 \mathrm{mmol} / \mathrm{L}$ reduced nicotinamide adenine dinucleotide (NADH). The reaction was initiated by the addition of $10 \mu \mathrm{L}$ of $2 \mathrm{mmol} / \mathrm{L}$ acetoacetyl-CoA. Absorbance at 340-nm wavelength was followed for $5 \mathrm{~min}$ with a spectrophotometer. CPT-I activity was assayed in whole lysates prepared from frozen epididymal adipose tissues as described previously [81].

\subsection{Quantitative RT-PCR of mRNA Expression}

Analysis of mRNA levels was performed as previously described [52]. Briefly, total RNA was isolated from epididymal adipose, hepatic tissues, and ileum using TRIzol (Invitrogen, Carlsbad, CA, USA). Complementary DNA (cDNA) was prepared by reverse transcription of 2 mg of total RNA using a first-strand cDNA synthesis kit (Takara Biotechnology, Dalian, China). RT-PCR was performed using LightCycler ${ }^{\circledR} 96$ (Roche, Mannheim, Germany). The sequences of primers are listed in Table S5 (Supplementary Materials).

\subsection{Immunoblot Analysis}

Epididymal fat and hepatic tissues were lysed in ice-cold condition with lysis buffer, and proteins were separated by protein gel electrophoresis, followed by transfer to a polyvinylidene difluoride membrane (Millipore, Boston, MA, USA). Later individual immunoblots were probed with antibodies. Finally, the band signal intensities were determined by Image J software [82]. The following primary antibodies were used: FAS, HSL, ERK1/2, p-ERK1/2, JNK, $p$-JNK, and eNOS antibodies (Cell Signaling Technology, Boston, MA, USA). PGC-1 $\alpha, \mathrm{NRF}-1, \mathrm{ERR} \alpha$, and UCP-1 antibodies were from Abcam (Cambridge, UK). $\beta$-Actin antibody was purchased from Bioss (Beijing, China).

\subsection{Statistical Analysis}

Data were expressed as means \pm standard deviations (SD). Data analysis was carried out using SPSS software (version 17.0 SPSS Inc., Chicago, IL, USA). Before performing one-factor ANOVA analysis, Levene's test was used to test for equal variance. After one-factor ANOVA, Duncan's post hoc test was used to evaluate differences between groups $(p<0.05)$.

Supplementary Materials: The following are available online. Figure S1: Effects of oral administration of BAA6 or AKK on fat mass and relative lean weight in HFD-fed mice; Figure S2: Enhanced inhibition effects of BAA6 or AKK on insulin resistance in HFD-fed mice; Figure S3: Effects of BAA6 or AKK on the lipid metabolism for liver in HFD-fed mice; Figure S4: Effects of BAA6 or AKK on the percentage of relative abundance for gut microbiota at the genus level in HFD-fed mice; Table S1: Effects of oral administration of BAA6 or AKK on food intake in HFD-fed mice; Table S2: Effects of oral administration of BAA6 or AKK on vitamin intake in HFD-fed mice; Table S3: Effects of oral administration of BAA6 or AKK on mineral intake in HFD-fed mice; Table S4: Composition of diets; Table S5: The sequences of primers used in epididymal adipose and liver tissues gene expression.

Author Contributions: Conceptualization, M.Z.; Data curation, Y.H. and X.L.; Formal analysis, Y.H., X.W. (Xiaoyu Wang) and X.W. (Xifan Wang); Funding acquisition, H.G. and M.Z.; Investigation, Y.H., X.W. (Xiaoyu Wang), X.W. (Xifan Wang), L.C., H.G. and Y.L.; Methodology, Y.H. and Y.L.; Project administration, M.Z.; Supervision, X.W. (Xiaoyu Wang), X.W. (Xifan Wang), M.Z. and Y.L.; Validation, Y.H., M.Z. and Y.L.; Visualization, Y.H.; Writing-original draft, Y.H.; Writing-review \& editing, Y.H., M.Z. and Y.L. All authors have read and agreed to the published version of the manuscript.

Funding: The research was supported in part by a grant from the National Natural Science Foundation of China (31601443) and the Beijing Science and Technology Project (Z181100009318005).

Conflicts of Interest: The authors declare no conflicts of interest. 


\section{References}

1. O'Neill, S.; O'Driscoll, L. Metabolic syndrome: A closer look at the growing epidemic and its associated pathologies. Obes. Rev. 2014, 16, 1-12. [CrossRef]

2. Dayan, P.H.; Sforzo, G.; Boisseau, N.; Pereira-Lancha, L.O.; Lancha, A.H. A new clinical perspective: Treating obesity with nutritional coaching versus energy-restricted diets. Nutrients 2019, 60, 147-151. [CrossRef]

3. Finicelli, M.; Squillaro, T.; Di Cristo, F.; Di Salle, A.; Melone, M.A.B.; Galderisi, U.; Peluso, G. Metabolic syndrome, mediterranean diet, and polyphenols: Evidence and perspectives. J. Cell. Physiol. 2018, 234, 5807-5826. [CrossRef]

4. Kong, C.; Gao, R.; Yan, X.; Huang, L.; Qin, H. Probiotics improve gut microbiota dysbiosis in obese mice fed a high-fat or high-sucrose diet. Nutrients 2019, 60, 175-184. [CrossRef]

5. Martini, F.; Iannelli, A.; Treacy, P.; Sebastianelli, L.; Schiavo, L. Perioperative complications of sleeve gastrectomy: Review of the literature. J. Minimal Access Surg. 2019, 15, 1-7. [CrossRef]

6. Bessesen, D.H.; Van Gaal, L.F. Progress and challenges in anti-obesity pharmacotherapy. Lancet Diabetes Endocrinol. 2017, 6, 237-248. [CrossRef]

7. Van Baarlen, P.; Wells, J.M.; Kleerebezem, M. Regulation of intestinal homeostasis and immunity with probiotic lactobacilli. Trends Immunol. 2013, 34, 208-215. [CrossRef]

8. Reid, G.; Younes, J.A.; Van Der Mei, H.C.; Gloor, G.B.; Knight, R.; Busscher, H.J. Microbiota restoration: Natural and supplemented recovery of human microbial communities. Nat. Rev. Genet. 2010, 9, 27-38. [CrossRef] [PubMed]

9. Stenman, L.; Waget, A.; Garret, C.; Klopp, P.; Burcelin, R.; Lahtinen, S. Potential probiotic Bifidobacterium animalis ssp. lactis 420 prevents weight gain and glucose intolerance in diet-induced obese mice. Benef. Microbes 2014, 5, 437-445. [CrossRef] [PubMed]

10. Savcheniuk, O.; Kobyliak, N.; Kondro, M.; Virchenko, O.; Falalyeyeva, T.; Beregova, T.V. Short-term periodic consumption of multiprobiotic from childhood improves insulin sensitivity, prevents development of non-alcoholic fatty liver disease and adiposity in adult rats with glutamate-induced obesity. BMC Complement. Altern. Med. 2014, 14, 247. [CrossRef] [PubMed]

11. Martorell, P.; Llopis, S.; González, N.; Chenoll, E.; López-Carreras, N.; Aleixandre, A.; Chen, Y.; Karoly, E.D.; Ramón, D.; Genovés, S. Probiotic strain Bifidobacterium animalisn subsp.lactis CECT 8145 reduces fat content and modulates lipid metabolism and antioxidant response in caenorhabditis elegans. J. Agric. Food Chem. 2016, 64, 3462-3472. [CrossRef] [PubMed]

12. Park, S.S.; Lee, Y.J.; Song, S.; Kim, B.; Kang, H.; Oh, S.; Kim, E. Lactobacillus acidophilus NS1 attenuates diet-induced obesity and fatty liver. J. Endocrinol. 2018, 237, 87-100. [CrossRef] [PubMed]

13. Wang, J.; Tang, H.; Zhang, C.; Zhao, Y.; Derrien, M.; Rocher, E.; Vlieg, J.E.T.V.H.; Strissel, K.; Zhao, L.; Obin, M.; et al. Modulation of gut microbiota during probiotic-mediated attenuation of metabolic syndrome in high fat diet-fed mice. ISME J. 2014, 9, 1-15. [CrossRef] [PubMed]

14. Chen, D.; Cao, S.; Chang, B.; Ma, T.; Gao, H.; Tong, Y.; Li, T.; Han, J.; Yi, X. Increasing hypothalamic nucleobindin 2 levels and decreasing hypothalamic inflammation in obese male mice via diet and exercise alleviate obesity-associated hypogonadism. Neuropeptides 2019, 74, 34-43. [CrossRef]

15. Shin, N.R.; Lee, J.C.; Lee, H.Y.; Kim, M.S.; Whon, T.W.; Lee, M.S.; Bae, J.W. An increase in the Akkermansia spp. population induced by metformin treatment improves glucose homeostasis in diet-induced obese mice. Gut 2013, 63, 727-735. [CrossRef]

16. Liu, Z.; Butow, R.A. Mitochondrial retrograde signaling. Annu. Rev. Genet. 2006, 40, 159-185. [CrossRef]

17. Shin, M.K.; Cheong, J.H. Mitochondria-centric bioenergetic characteristics in cancer stem-like cells. Arch. Pharmacal Res. 2019, 42, 113-127. [CrossRef]

18. Hioki, C.; Yoshida, T.; Kogure, A.; Takakura, Y.; Umekawa, T.; Yoshioka, K.; Shimatsu, A.; Yoshikawa, T. Effects of growth hormone (GH) on mRNA levels of uncoupling proteins 1, 2, and 3 in brown and white adipose tissues and skeletal muscle in obese mice. Horm. Metab. Res. 2004, 36, 607-613. [CrossRef]

19. Hirabara, S.M.; Curi, R.; Maechler, P. Saturated fatty acid-induced insulin resistance is associated with mitochondrial dysfunction in skeletal muscle cells. J. Cell. Physiol. 2010, 222, 187-194. [CrossRef]

20. Nisoli, E.; Clementi, E.; Paolucci, C.; Cozzi, V.; Tonello, C.; Sciorati, C.; Bracale, R.; Valerio, A.; Francolini, M.; Moncada, S.; et al. Mitochondrial biogenesis in mammals: The role of endogenous nitric oxide. Science 2003, 299, 896-899. [CrossRef] 
21. Isokpehi, R.D.; Simmons, S.S.; Johnson, M.; Payton, M. Genomic evidence for bacterial determinants influencing obesity development. Int. J. Environ. Res. Public Heal. 2017, 14, 345. [CrossRef] [PubMed]

22. Galmés-Pascual, B.M.; Nadal-Casellas, A.; Thorbrügge, M.B.; Sbert-Roig, M.; García-Palmer, F.J.; Proenza, A.M.; Gianotti, M.; Llado, I. 17 $\beta$-estradiol improves hepatic mitochondrial biogenesis and function through PGC1B. J. Endocrinol. 2017, 232, 297-308. [CrossRef] [PubMed]

23. Sun, E.; Zhao, L.; Ren, F.; Liu, S.; Zhang, M.; Guo, H. Complete genome sequence of Bifidobacterium animalis subsp. lactis A6, a probiotic strain with high acid resistance ability. J. Biotechnol. 2015, 200, 8-9. [CrossRef] [PubMed]

24. Song, J.J.; Wang, Q.; Du, M.; Li, T.G.; Chen, B.; Mao, X.Y. Casein glycomacropeptide-derived peptide IPPKKNQDKTE ameliorates high glucose-induced insulin resistance in HepG2 cells via activation of AMPK signaling. Mol. Nutr. Food Res. 2016, 61, 1600301. [CrossRef]

25. Pi-Sunyer, X. The medical risks of obesity. Postgrad. Med. 2009, 121, 21-33. [CrossRef]

26. Cani, P.D.; Amar, J.; Iglesias, M.A.; Poggi, M.; Knauf, C.; Bastelica, D.; Neyrinck, A.M.; Fava, F.; Tuohy, K.; Chabo, C.; et al. Metabolic endotoxemia initiates obesity and insulin resistance. Diabetes 2007, 56, 1761-1772. [CrossRef]

27. Yoshizumi, M.; A Perrella, M.; Burnett, J.C.; Lee, M.E. Tumor necrosis factor downregulates an endothelial nitric oxide synthase mRNA by shortening its half-life. Circ. Res. 1993, 73, 205-209. [CrossRef]

28. Molinaro, F.; Paschetta, E.; Cassader, M.; Gambino, R.; Musso, G. Probiotics, prebiotics, energy balance, and obesity. Gastroenterol. Clin. North Am. 2012, 41, 843-854. [CrossRef]

29. Pedret, A.; Valls, R.M.; Calderón-Pérez, L.; Llauradó, E.; Companys, J.; Pagà, L.P.; Moragas, A.; Martín-Luján, F.; Ortega, Y.; Giralt, M.; et al. Effects of daily consumption of the probiotic Bifidobacterium animalis subsp. lactis CECT 8145 on anthropometric adiposity biomarkers in abdominally obese subjects: A randomized controlled trial. Int. J. Obes. 2018, 43, 1863-1868. [CrossRef]

30. Gu, Y.; Liu, C.; Zheng, N.; Jia, W.; Zhang, W.; Li, H. Metabolic and gut microbial characterization of obesity-prone mice under a high-fat diet. J. Proteome Res. 2019, 18, 1703-1714. [CrossRef]

31. Poggi, M.; Bastelica, D.; Gual, P.; Iglesias, M.A.; Gremeaux, T.; Knauf, C.; Peiretti, F.; Verdier, M.; Juhan-Vague, I.; Tanti, J.F.; et al. $\mathrm{C} 3 \mathrm{H} / \mathrm{HeJ}$ mice carrying a toll-like receptor 4 mutation are protected against the development of insulin resistance in white adipose tissue in response to a high-fat diet. Diabetol. 2007, 50, 1267-1276. [CrossRef] [PubMed]

32. Song, J.J.; Tian, W.J.; Kwok, L.-Y.; Wang, Y.L.; Shang, Y.N.; Menghe, B.; Wang, J.G. Effects of microencapsulated Lactobacillus plantarum LIP-1 on the gut microbiota of hyperlipidaemic rats. Br. J. Nutr. 2017, 118, 481-492. [CrossRef] [PubMed]

33. Li, K.; Zhang, L.; Xue, J.; Yang, X.; Dong, X.; Sha, L.; Lei, H.; Zhang, X.; Zhu, L.; Wang, Z.; et al. Dietary inulin alleviates diverse stages of type 2 diabetes mellitus via anti-inflammation and modulating gut microbiota in db/db mice. Food Funct. 2019, 10, 1915-1927. [CrossRef] [PubMed]

34. Zhao, S.; Liu, W.; Wang, J.; Shi, J.; Sun, Y.; Wang, W.; Ning, G.; Liu, R.-X.; Hong, J. Akkermansia muciniphila improves metabolic profiles by reducing inflammation in chow diet-fed mice. J. Mol. Endocrinol. 2017, 58, 1-14. [CrossRef]

35. Hu, Q.; Zhuo, Z.; Fang, S.; Zhang, Y.; Feng, J. Phytosterols improve immunity and exert anti-inflammatory activity in weaned piglets. J. Sci. Food Agric. 2017, 97, 4103-4109. [CrossRef]

36. Yoo, S.R.; Kim, Y.J.; Park, D.Y.; Jung, U.J.; Jeon, S.M.; Ahn, Y.T.; Huh, C.S.; McGregor, R.; Choi, M.S. Probiotics L. plantarum and L. curvatusin combination alter hepatic lipid metabolism and suppress diet-induced obesity. Obesity 2013, 21, 2571-2578. [CrossRef]

37. Díaz, E.O.; Galgani, J.E.; Aguirre, C.A.; Atwater, I.J.; Burrows, R. Erratum: Effect of glycemic index on whole-body substrate oxidation in obese women. Int. J. Obes. 2005, 29, 879. [CrossRef]

38. Wang, L.; Chen, C.; Cui, S.; Lee, Y.-K.; Wang, G.; Zhao, J.; Zhang, H.; Chen, W. Adhesive Bifidobacterium induced changes in cecal microbiome alleviated constipation in mice. Front. Microbiol. 2019, 10, 1721. [CrossRef]

39. Liang, Y.; Liang, S.; Zhang, Y.; Deng, Y.; He, Y.; Chen, Y.; Liu, C.; Lin, C.; Yang, Q. Oral administration of compound probiotics ameliorates HFD-induced gut microbe dysbiosis and chronic metabolic inflammation via the $\mathrm{G}$ protein-coupled receptor 43 in non-alcoholic fatty liver disease rats. Probiotics Antimicrob. Proteins 2018, 11, 175-185. [CrossRef] 
40. Li, T.; Gao, J.; Du, M.; Mao, X. Milk fat globule membrane supplementation modulates the gut microbiota and attenuates metabolic endotoxemia in high-fat diet-fed mice. J. Funct. Foods 2018, 47, 56-65. [CrossRef]

41. Ormerod, K.L.; Wood, D.L.A.; Lachner, N.; Gellatly, S.; Daly, J.N.; Parsons, J.D.; Dal'Molin, C.G.O.; Palfreyman, R.; Nielsen, L.K.; Cooper, M.A.; et al. Genomic characterization of the uncultured Bacteroidales family S24-7 inhabiting the guts of homeothermic animals. Microbiome 2016, 4, 36. [CrossRef] [PubMed]

42. Evans, C.C.; LePard, K.J.; Kwak, J.W.; Stancukas, M.C.; Laskowski, S.; Dougherty, J.; Moulton, L.; Glawe, A.; Wang, Y.; Leone, V.; et al. Exercise prevents weight gain and alters the gut microbiota in a mouse model of high fat diet-induced obesity. PLoS ONE 2014, 9, e92193. [CrossRef] [PubMed]

43. Yu, D.Y.; Kim, S.H.; Kim, J.A.; Kim, I.S.; Moon, Y.S.; Lee, S.S.; Park, H.C.; Jung, J.H.; Chung, Y.H.; Shin, D.; et al. Effects of Rubus coreanus byproducts on intestinal microbiota and the immune modulation. Asian-Australasian J. Anim. Sci. 2018, 31, 429-438. [CrossRef] [PubMed]

44. Węglarz, L.; Wawszczyk, J.; Orchel, A.; Jaworska-Kik, M.; Dzierżewicz, Z. Phytic acid modulates in vitro IL-8 and IL-6 release from colonic epithelial cells stimulated with LPS and IL-1ß. Dig. Dis. Sci. 2006, 52, 93-102. [CrossRef] [PubMed]

45. Martinez-Medina, M.; Denizot, J.; Dreux, N.; Robin, F.; Billard, E.; Bonnet, R.; Darfeuille-Michaud, A.; Barnich, N. Western diet induces dysbiosis with increased E coli in CEABAC10 mice, alters host barrier function favouring AIEC colonisation. Gut 2014, 63, 116-124. [CrossRef] [PubMed]

46. Vieira, A.; Fukumori, C.; Ferreira, C.M. New insights into therapeutic strategies for gut microbiota modulation in inflammatory diseases. Clin. Transl. Immunol. 2016, 5, e87. [CrossRef]

47. Weiss, G. Intestinal irony: How probiotic bacteria outcompete bad bugs. Cell Host Microbe 2013, 14 , 3-4. [CrossRef]

48. Hammerman, C.; Bin-Nun, A.; Kaplan, M. Germ warfare: Probiotics in defense of the premature gut. Clin. Perinatol. 2004, 31, 489-500. [CrossRef]

49. Lin, P.W.; Nasr, T.R.; Berardinelli, A.J.; Kumar, A.; Neish, A.S. The probiotic Lactobacillus GG may augment intestinal host defense by regulating apoptosis and promoting cytoprotective responses in the developing murine gut. Pediatr. Res. 2008, 64, 511-516. [CrossRef]

50. Resta-Lenert, S.; Barrett, K.E. Probiotics and commensals reverse TNF- $\alpha$ - and IFN- $\gamma-$ induced dysfunction in human intestinal epithelial cells. Gastroenterology 2006, 130, 731-746. [CrossRef]

51. Dewulf, E.M.; Cani, P.D.; Claus, S.P.; Fuentes, S.; Puylaert, P.G.; Neyrinck, A.M.; Bindels, L.B.; De Vos, W.M.; Gibson, G.R.; Thissen, J.P.; et al. Insight into the prebiotic concept: Lessons from an exploratory, double blind intervention study with inulin-type fructans in obese women. Gut 2013, 62, 1112-1121. [CrossRef] [PubMed]

52. Sun, J.; Ren, F.; Xiong, L.; Zhao, L.; Guo, H. Bovine lactoferrin suppresses high-fat diet induced obesity and modulates gut microbiota in C57BL/6J mice. J. Funct. Foods 2016, 22, 189-200. [CrossRef]

53. Valerio, A.; Cardile, A.; Cozzi, V.; Bracale, R.; Tedesco, L.; Pisconti, A.; Palomba, L.; Cantoni, O.; Clementi, E.; Moncada, S.; et al. TNF- $\alpha$ downregulates eNOS expression and mitochondrial biogenesis in fat and muscle of obese rodents. J. Clin. Investig. 2006, 116, 2791-2798. [CrossRef] [PubMed]

54. Hotamisligil, G.; Shargill, N.; Spiegelman, B. Adipose expression of tumor necrosis factor-alpha: Direct role in obesity-linked insulin resistance. Science 1993, 259, 87-91. [CrossRef]

55. Dumitru, C.D.; Ceci, J.D.; Tsatsanis, C.; Kontoyiannis, D.; Stamatakis, K.; Lin, J.-H.; Patriotis, C.; A Jenkins, N.; Copeland, N.G.; Kollias, G.; et al. TNF- $\alpha$ Induction by LPS is regulated posttranscriptionally via a Tp12/ERK-dependent pathway. Cell 2000, 103, 1071-1083. [CrossRef]

56. SchĘchinger, V.; Britten, M.B.; Zeiher, A.M. Prognostic impact of coronary vasodilator dysfunction on adverse long-term outcome of coronary heart disease. Circulation 2000, 101, 1899-1906. [CrossRef]

57. Lei, P.; Tian, S.; Teng, C.; Huang, L.; Liu, X.; Wang, J.; Zhang, Y.; Li, B.; Shan, Y. Sulforaphane improves lipid metabolism by enhancing mitochondrial function and biogenesis in vivo and in vitro. Mol. Nutr. Food Res. 2019, 63, 1800795. [CrossRef]

58. Tsutsumi, R.; Yoshida, T.; Nii, Y.; Okahisa, N.; Iwata, S.; Tsukayama, M.; Hashimoto, R.; Taniguchi, Y.; Sakaue, H.; Hosaka, T.; et al. Sudachitin, a polymethoxylated flavone, improves glucose and lipid metabolism by increasing mitochondrial biogenesis in skeletal muscle. Nutr. Metab. 2014, 11, 32. [CrossRef]

59. Winkler, G.; Lakatos, P.; Salamon, F.; Nagy, Z.; Speer, G.; Kovacs, M.; Harmos, G.; Dworak, O.; Cseh, K. Elevated serum TNF-alpha level as a link between endothelial dysfunction and insulin resistance in normotensive obese patients. Diabet. Med. 1999, 16, 207-211. [CrossRef] 
60. Lira, V.A.; Brown, D.L.; Lira, A.K.; Kavazis, A.N.; Soltow, Q.A.; Zeanah, E.H.; Criswell, D.S. Nitric oxide and AMPK cooperatively regulate PGC-1 $\alpha$ in skeletal muscle cells. J. Physiol. 2010, 588, 3551-3566. [CrossRef]

61. Wang, L.; Mascher, H.; Psilander, N.; Blomstrand, E.; Sahlin, K. Resistance exercise enhances the molecular signaling of mitochondrial biogenesis induced by endurance exercise in human skeletal muscle. J. Appl. Physiol. 2011, 111, 1335-1344. [CrossRef] [PubMed]

62. Zhang, H.Q.; Chen, S.Y.; Wang, A.S.; Yao, A.J.; Fu, J.F.; Zhao, J.S.; Chen, F.; Zou, Z.Q.; Zhang, X.; Shan, Y.J.; et al. Sulforaphane induces adipocyte browning and promotes glucose and lipid utilization. Mol. Nutr. Food Res. 2016, 60, 2185-2197. [CrossRef]

63. Kleiner, S.; Mepani, R.J.; Laznik, D.; Ye, L.; Jurczak, M.J.; Jornayvaz, F.R.; Estall, J.L.; Bhowmick, D.C.; Shulman, G.I.; Spiegelman, B.M. Development of insulin resistance in mice lacking PGC-1 $\alpha$ in adipose tissues. Proc. Natl. Acad. Sci. USA 2012, 109, 9635-9640. [CrossRef] [PubMed]

64. Scarpulla, R.C. Transcriptional paradigms in mammalian mitochondrial biogenesis and function. Physiol. Rev. 2008, 88, 611-638. [CrossRef] [PubMed]

65. Virbasius, J.; Scarpulla, R.C. Activation of the human mitochondrial transcription factor A gene by nuclear respiratory factors: A potential regulatory link between nuclear and mitochondrial gene expression in organelle biogenesis. Proc. Natl. Acad. Sci. USA 1994, 91, 1309-1313. [CrossRef] [PubMed]

66. Bergeron, R.; Ren, J.M.; Cadman, K.S.; Moore, I.K.; Perret, P.; Pypaert, M.; Young, L.H.; Semenkovich, C.F.; Shulman, G.I. Chronic activation of AMP kinase results in NRF-1 activation and mitochondrial biogenesis. Am. J. Physiol. Metab. 2001, 281, E1340-E1346. [CrossRef]

67. Kerner, J.; Hoppel, C. Fatty acid import into mitochondria. Biochim. et Biophys. Acta (BBA) - Mol. Cell Boil. Lipids 2000, 1486, 1-17. [CrossRef]

68. Rector, R.S.; Uptergrove, G.M.; Borengasser, S.J.; Mikus, C.R.; Morris, E.M.M.; Naples, S.P.; Laye, M.; Laughlin, M.H.; Booth, F.W.; Ibdah, J.A.; et al. Changes in skeletal muscle mitochondria in response to the development of type 2 diabetes or prevention by daily wheel running in hyperphagic OLETF rats. Am. J. Physiol. Metab. 2010, 298, E1179-E1187. [CrossRef]

69. Huss, J.M.; Kelly, D.P. Nuclear receptor signaling and cardiac energetics. Circ. Res. 2004, 95, 568-578. [CrossRef]

70. Lowell, B.B.; Spiegelman, B.M. Towards a molecular understanding of adaptive thermogenesis. Nature 2000, 404, 652-660. [CrossRef]

71. Tomas, E.; Stanojevic, V.; McManus, K.; Khatri, A.; Everill, P.; Bachovchin, W.W.; Habener, J.F. GLP-1(32-36)amide pentapeptide increases basal energy expenditure and inhibits weight gain in obese mice. Diabetes 2015, 64, 2409-2419. [CrossRef] [PubMed]

72. Clemente, J.C.; Ursell, L.K.; Parfrey, L.W.; Knight, R. The impact of the gut microbiota on human health: An integrative view. Cell 2012, 148, 1258-1270. [CrossRef] [PubMed]

73. Louis, P.; Flint, H.J. Diversity, metabolism and microbial ecology of butyrate-producing bacteria from the human large intestine. FEMS Microbiol. Lett. 2009, 294, 1-8. [CrossRef] [PubMed]

74. Schneeberger, M.; Everard, A.; Gómez-Valadés, A.G.; Matamoros, S.; Ramírez, S.; Delzenne, N.M.; Gomis, R.; Claret, M.; Cani, P.D. Akkermansia muciniphila inversely correlates with the onset of inflammation, altered adipose tissue metabolism and metabolic disorders during obesity in mice. Sci. Rep. 2015, 5, 16643. [CrossRef]

75. Li, Y.; Wong, K.; Giles, A.J.; Jiang, J.; Lee, J.W.; Adams, A.C.; Kharitonenkov, A.; Yang, Q.; Gao, B.; Guarente, L.; et al. Hepatic SIRT1 attenuates hepatic steatosis and controls energy balance in mice by inducing fibroblast growth factor 21. Gastroenterology 2014, 146, 539-549. [CrossRef]

76. Fang, B.; Li, J.W.; Zhang, M.; Ren, F.Z.; Pang, G.F. Chronic chlorpyrifos exposure elicits diet-specific effects on metabolism and the gut microbiome in rats. Food Chem. Toxicol. 2018, 111, 144-152. [CrossRef]

77. Li, T.; Gao, J.; Du, M.; Mao, X. Bovine $\alpha$-lactalbumin hydrolysates ameliorate obesity-associated endotoxemia and inflammation in high-fat diet-fed mice through modulation of gut microbiota. Food Funct. 2019, 10, 3368-3378. [CrossRef]

78. Huang, J.; Lin, X.; Xue, B.; Luo, J.; Gao, L.; Wang, Y.; Ou, S.; Peng, X. Impact of polyphenols combined with high-fat diet on rats' gut microbiota. J. Funct. Foods 2016, 26, 763-771. [CrossRef]

79. Wei, L.; Huang, C.; Yang, H.; Li, M.; Yang, J.; Qiao, X.; Mu, L.; Xiong, F.; Wu, J.; Xu, W. A potent anti-inflammatory peptide from the salivary glands of horsefly. Parasites Vectors 2015, 8, 556. [CrossRef] 
80. He, M.C.; Shi, Z.; Sha, N.N.; Chen, N.; Peng, S.Y.; Liao, D.F.; Wong, M.S.; Dong, X.L.; Wang, Y.; Yuan, T.F.; et al. Paricalcitol alleviates lipopolysaccharide-induced depressive-like behavior by suppressing hypothalamic microglia activation and neuroinflammation. Biochem. Pharmacol. 2019, 163, 1-8. [CrossRef]

81. Tsuda, M.; Fukushima, A.; Matsumoto, J.; Takada, S.; Kakutani, N.; Nambu, H.; Yamanashi, K.; Furihata, T.; Yokota, T.; Okita, K.; et al. Protein acetylation in skeletal muscle mitochondria is involved in impaired fatty acid oxidation and exercise intolerance in heart failure. J. Cachex-Sarcopenia Muscle 2018, 9, 844-859. [CrossRef] [PubMed]

82. Hong, J.H.; Hwang, E.Y.; Kim, H.J.; Jeong, Y.J.; Lee, I.S. Artemisia capillaris inhibits lipid accumulation in 3T3-L1 adipocytes and obesity in C57BL/6J mice fed a high fat diet. J. Med. Food 2009, 12, 736-745. [CrossRef] [PubMed]

(C) 2020 by the authors. Licensee MDPI, Basel, Switzerland. This article is an open access article distributed under the terms and conditions of the Creative Commons Attribution (CC BY) license (http://creativecommons.org/licenses/by/4.0/). 